\title{
The role of epistemic beliefs and epistemic emotions in online learning
}

\section{DOI: http://doi.org/10.26758/9.1.7}

Diego Oswaldo CAMACHO VEGA

Autonomous University of Baja California, Faculty of Medicine and Psychology

Adress correspondence to: Diego Oswaldo Camacho Vega, Autonomous University of Baja California, Faculty of Medicine and Psychology, Avenida Álvaro Obregón sin número, Colonia Nueva Mexicali, Baja California, México. C.P. 21100, Ph.: 016-646-821-233;

E-mail: diego.camacho@uabc.edu.mx

\begin{abstract}
Objectives. The aimed objectives of this study are 1) to determine which factors of epistemic beliefs are significant in an online course, 2) to determine if positive or negative epistemic emotions are significant in an online course, and 3) to identify the existence of a correlation between epistemic belief and epistemic emotions in an online.

Material and methods. The Epistemic Belief Inventory and the Epistemic Emotions Scales Short-Form were administrated to 30 students at the Faculty of Medicine and Psychology from the Autonomous University of Baja California after taking a 36-weeks online course.

Results. The results showed higher scores for positive epistemic emotions and lowers scores for negative epistemic emotions. Pearson's coefficient indicates a negatively moderate correlation between positive and negative emotions and two factors from the epistemic belief inventory.

Conclusions. This research supports the importance of epistemic beliefs in epistemic emotions when students learn through online courses participating in the growing body of evidence on this topic.
\end{abstract}

Keywords: epistemic beliefs, epistemic emotions, online learning.

\section{Introduction}

There is a growing body of evidence about the influence of Epistemic Belief have in learning processes (Trevors et. al, 2016). The epistemic beliefs refers to "beliefs about the nature of knowledge [...], these may include beliefs about the certainty, the source, the justification, the acquisition, and the structure of Knowledge" (Duell and Schommer-Aikins, 2001, p. 419). The epistemic beliefs could be expressed in five main kinds of beliefs: 1) Omniscient Authority; 2) Certain Knowledge; 3) Quick Learning; 4) Simple Knowledge; and 5) Innate Ability (Leal-Soto and Ferrer-Urbina, 2017).

On the other hand, epistemic emotions have demonstrated an important role in learning (Trevors et al., 2017). Epistemic emotions refer to emotions that result when the object of the students focus is on knowledge learning, that means that the most important for the learner is the self-knowledge (Muis et al., 2015). Several epistemic emotions have been considered to understand their impact in learning such as surprise, enjoyment, anxiety, and boredom (Muis et al., 2015) based in the academic emotions developed by Pekrun et al. (2011).

However, if there is a growing body of evidence about epistemic beliefs and epistemic emotions demonstrating an important role in areas such as climate change (Bråten and Strømsø, 2009) and mathematics learning (Muis et al., 2015), the relation between them is not clear. In 
addition, the study of epistemic beliefs and epistemic emotion in other learning environments such as online have not been considered yet

Thus, the aimed objectives of this research are 1) to determine which factors of epistemic beliefs are significant in an online course, 2) to determine if positive or negative epistemic emotions are significant in an online course, and 3) to identify the existence of a correlation between epistemic belief and epistemic emotions in an online. Finally, our hypothesis for this study is expressed as following:

1) There are similar scores of epistemic belief and positive epistemic emotions when students take an online course.

2) There is a correlation between epistemic belief and epistemic emotions when students take an online course.

\section{Material and methods}

\section{Participants}

For the current study 30 first-year students who took an online course about educational technology in a Psychology bachelor from one of the largest universities in Mexico where considered $($ female $=21 ;$ male $=9$, age average $=19.77)$.

\section{Procedures}

The procedure consisted of the adaptation of a mandatory course in an online modality. The adaptation consisted in the creation of goals categorized in five units with readings, video tutorials, forums, and quizzes completely online for 36 weeks. At the end of the course, participants voluntarily responded to informed consent, the Epistemic Beliefs Inventory developed by Schraw, Bendixen and Dunkle (2002) and translated to a Spanish version by LealSoto and Ferrer-Urbina (2017). In addition, a translated version of the Epistemic Emotions Scales - Short-Form (Pekrun et al., 2016) was administrated. To ensure equivalence, the translation consisted of a three steps procedure (Spanish-English-Spanish) translation made by three different highly proficient experts in the topic. The statistical analysis consisted of the calculation of descriptive for each instrument (means and standard deviations), and the calculation of correlation using parametric statistics.

\section{Instruments}

After taking the online course students responded to the Epistemic Belief Inventory and the Epistemic Emotions Scales - Short-Form. The Epistemic Belief Inventory (EBI) is a 32-item questionnaire of 5-point Likert-type rating scale from strongly disagree (1) to strongly agree (5). It measures the five factors beforehand mentioned in the introduction: 1) Certain Knowledge (CK) for example "absolute moral truth does not exist", 2) Innate Ability (IA) for example "some people will never be smart no matter how hard they work", 3) Quick Learning (QL) for example "if you do not learn something quickly, you will never learn it", 4) Simple Knowledge (SK) for example "too many theories just complicate things", and Omniscient Authority (OA) for example "children should be allowed to question their parents' authority". For its part, the Epistemic Emotions Scales - Short-Form (EES-SF) consists of a 7-item questionnaire of 5-point Likert-type rating how strongly they felt each of the emotions: curiosity, enjoyment, surprise (positive), and confusion, anxiety, frustration, boredom in a 1 to 5 scale. The EES-SF was translated to the Spanish language as well as the EBI. In addition, demographic questions age and gender were included in the questionnaire. 


\section{Results}

The statistical analysis consisted of the calculation of descriptive (means and standard deviation) to aim the first and second objectives of our research: to determine which factors of epistemic beliefs are significant in an online course, and to determine if positive or negative epistemic emotions are significant in an online course, following by the calculation of Pearson's coefficient $(r)$ to answer the second objective: to identify the existence of correlation between epistemic belief and epistemic emotions in an online course. Due to the sample size a confirmatory analysis was not calculated.

As is shown in Table 1, Descriptive indicate low scores for epistemic beliefs $(\mathrm{M}=2.84$, $\mathrm{SD}=3.40)$, while positive emotions showed higher values $(\mathrm{M}=3.77, \mathrm{SD}=7.31)$ opposite to negative emotions which obtained lower values $(\mathrm{M}=2.24, \mathrm{SD}=2.51)$ (See Table 1).

Table 1. Descriptive and correlation values by factor

\begin{tabular}{|c|c|c|c|c|c|c|c|}
\hline & & & & \multicolumn{2}{|c|}{ EESPositive } & \multicolumn{2}{|c|}{ EES $_{\text {NEGATIVE }}$} \\
\hline item & Factor & MEAN & SD & $r$ & $p$ & $r$ & $p$ \\
\hline $\begin{array}{l}\text { EBI1 } \\
\text { EBI10 } \\
\text { EBI11 } \\
\text { EBI13 } \\
\text { EBI18 } \\
\text { EBI22 } \\
\text { EBI24 } \\
\text { EBI30 }\end{array}$ & SK & 2.96 & 0.40 & -.420 & $0.02 *$ & -.415 & $0.02 *$ \\
\hline $\begin{array}{l}\text { EBI2 } \\
\text { EBI6 } \\
\text { EBI14 } \\
\text { EBI19 } \\
\text { EBI23 } \\
\text { EBI25 } \\
\text { EBI31 }\end{array}$ & CK & 2.47 & 0.37 & $-.398^{*}$ & 0.03 & $-.498 * *$ & 0.01 \\
\hline $\begin{array}{l}\text { EBI3 } \\
\text { EBI9 } \\
\text { EBI16 } \\
\text { EBI21 } \\
\text { EBI29 }\end{array}$ & QL & 3.00 & 0.56 & -0.34 & 0.07 & -0.13 & 0.50 \\
\hline $\begin{array}{l}\text { EBI4 } \\
\text { EBI7 } \\
\text { EBI20 } \\
\text { EBI27 } \\
\text { EBI28 } \\
\end{array}$ & OA & 2.91 & 0.46 & -0.35 & 0.06 & -0.25 & 0.18 \\
\hline $\begin{array}{l}\text { EBI5 } \\
\text { EBI8 } \\
\text { EBI12 } \\
\text { EBI15 } \\
\text { EBI17 } \\
\text { EBI26 } \\
\text { EBI32 } \\
\end{array}$ & IA & 2.93 & 0.48 & -0.27 & 0.15 & -0.21 & 0.26 \\
\hline $\begin{array}{l}\text { EEPOSITIVE } \\
\text { EENEGATIVE }\end{array}$ & $\mathrm{EE}$ & $\begin{array}{l}3.77 \\
2.24\end{array}$ & $\begin{array}{l}0.68 \\
0.88\end{array}$ & & & & \\
\hline
\end{tabular}

Note: $\mathrm{r}=$ Pearson's coefficient values; ${ }^{*} p=$ Significant value at .05 
On the other hand, the Pearson's coefficient $(r)$ showed negatively significant correlations and significant $p$ value for both positive and negative epistemic emotions regarding

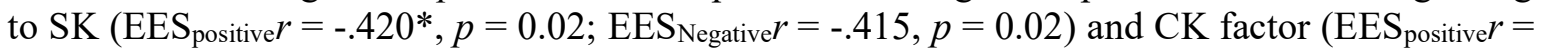
$-.398, p=0.03 ; r=-.498, p=0.01)$.

\section{Discussions}

The results of this study only confirm the first hypothesis for the Quick Learning (QL) factor which obtained higher scores as well as positive emotions which is a positive issue for online learning. Regarding the second hypothesis, effectively results confirm that there is a correlation between epistemic belief and epistemic emotions when students take an online course.

Surprisingly, the results were significant for positive and negative epistemic emotions supporting the inconsistencies reported by (Leal-Soto and Ferrer-Urbina, 2017) due in both cases there is a moderate negative correlation according to the criterion suggested by Hair et al. (2006). Nonetheless, it is clear that lower scores in SK $(M=2.96)$, and CK $(M=2.47)$ are negatively correlated with higher values for positive epistemic emotions $(M=3.77)$, while lower scores in SK and CK scores are negatively correlated to lower values for negative epistemic emotions ( $M$ $=2.24)$.

That means that lower levels of Simple Knowledge, for example "It bothers me when instructors don't tell students the answers to complicated problems" (SK) and Certain Knowledge such as "If two people are arguing about something, at least one of them must be wrong" could predicts negatively some positive epistemic emotions (curiosity, enjoy, surprise). In other words, the decreasing of scores in SK and CK factors is correlated to the increase of scores in positive epistemic emotions. Instead, lower scores Simple Knowledge and Certain knowledge could predict negatively in lower levels of negative emotions (confusion, anxiety, frustration, boring) which indicates that lower scores in SK and CK factors trend to decrease negative epistemic emotions.

These results are consistent about the importance of epistemic belief in learning environments (Trevors et al., 2016) being an important variable in the development of learning including the online based learning. Also, this study supports the evidence about the importance of emotions in the process learning because epistemic emotions have demonstrated to be an important factor to mediate complex relations between epistemic beliefs and fundamental learning outcomes (Trevors et al., 2017).

\section{Conclusions}

In conclusion, this research contributes in a theoretical and methodological way in the understanding of a growing body of evidence about epistemic belief and epistemic emotions in learning environments, particularly in online environments, showing the importance of the analysis of cognition in the understanding of emerging emotions in education., Its relevance has been widely evidenced in themes such as climate change (Bråten and Strømsø, 2009) and mathematics (Muis et al., 2015b) as mentioned in the introduction, and it could be important to evaluate this variable in other themes such as health. For its part, the results showed that a decrease in some epistemic beliefs could decrease negative epistemic emotions (i.e. confusion, anxiety, frustration, boring) and increase positive epistemic emotions (i.e. curiosity, enjoy, surprise) facilitating the learning processes in online learning. However, this research has some limitations. The principal limitations are the sample size because it was not possible to calculate a confirmatory analysis. Second, further research is necessary to understand the role of Quick Learning in online environments. Finally, there is important to consider a future study including 
a control group to determine if the importance of Simple Knowledge and Certain Knowledge are an important factor for traditional courses just like online learning of if there are significant differences.

\section{Bibliography}

1. Bråten, I. and Strømsø, H.I., 2009. Effects of Task Instruction and Personal Epistemology on the Understanding of Multiple Texts About Climate Change. Discourse Processes, [ejournal] 47(1), pp. 1-31, https://doi.org/10.1080/01638530902959646.

2. Duell, O.K. and Schommer-Aikins, M., 2001. Measures of People's Beliefs About Knowledge and Learning. Educational Psychology Review, 13, pp. 419-449.

3. Hair, J., Black, W., Babin, B., Anderson, R. and Tatham, R., 2006. Multivariate Data Analysis. Upper Saddle River: Pearson Prentice Hall.

4. Leal-Soto, F. and Ferrer-Urbina, R., 2017. Three-factor structure for Epistemic Belief Inventory: A cross-validation study. PLOS ONE, [e-journal] 12(3), pp. 1-16, https://doi.org/10.1371/journal.pone.0173295.

5. Muis, K.R., Psaradellis, C., Lajoie, S.P., Di Leo, I. and Chevrier, M., 2015. The role of epistemic emotions in mathematics problem-solving. Contemporary Educational Psychology, [e-journal] 42, pp. 172-185, https://doi.org/10.1016/j.cedpsych.2015.06.003.

6. Pekrun, R., Vogl, E., Muis, K.R. and Sinatra, G.M., 2016. Measuring emotions during epistemic activities: The epistemically-related emotion scales. Cognition and Emotion, 22 (0), pp. 1-9.

7. Pekrun, R., Goetz, T., Frenzel, A.C., Barchfeld, P. and Perry, R.P., 2011. Measuring emotions in students' learning and performance: The Achievement Emotions Questionnaire (AEQ). Contemporary Educational Psychology, [e-journal] 36(1), pp. 36-48. https://doi.org/10.1016/j.cedpsych.2010.10.002.

8. Schraw, G., Bendixen, L.D. and Dunkle, M.E., 2002. Development and evaluation of the Epistemic Belief Inventory (EBI). In: Hofer BK, Pintrich PR, editors. Personal Epistemology: The psychology of beliefs about knowledge and knowing. Mahwah, NJ: Lawrence Erlbaum Associates; 2002, pp. 261-275.

9. Trevors, G., Feyzi-Behnagh, R., Azevedo, R. and Bouchet, F., 2016. Self-regulated learning processes vary as a function of epistemic beliefs and contexts: Mixed method evidence from eye tracking and concurrent and retrospective reports. Learning and Instruction, [e-journal] 42, pp. 31-46, https://doi.org/10.1016/j.learninstruc.2015.11.003.

10. Trevors, G.J., Muis, K.R., Pekrun, R., Sinatra, G.M. and Muijselaar, M.M.L., 2017. Exploring the relations between epistemic beliefs, emotions, and learning from texts. Contemporary Educational Psychology, [e-journal] 48, pp. 116-132, https://doi.org/10.1016/j.cedpsych.2016.10.001. 